\title{
A Proposed Systemic Modeling Software for Jujube Fruit Cracking
}

\author{
Yanbin Hua1, Yuqin Song1, Jie Li11,2, Caifang Tian'1, Xin-Gen Zhou ${ }^{3 *}$, Liulin Li1* \\ ${ }^{1}$ College of Horticulture, Shanxi Agricultural University, Taigu, Shanxi, China \\ ${ }^{2}$ College of Forestry, Shanxi Agricultural University, Taigu, Shanxi, China \\ ${ }^{3}$ AgriLife Research and Extension Center, Texas A\&M University System, Beaumont, TX, USA \\ Email: ${ }^{*}$ xzhou@aesrg.tamu.edu, ${ }^{*}$ tgliulin@163.com
}

Received 31 January 2015; accepted 8 March 2015; published 11 March 2015

Copyright (C) 2015 by authors and Scientific Research Publishing Inc.

This work is licensed under the Creative Commons Attribution International License (CC BY). http://creativecommons.org/licenses/by/4.0/

(c) (i) Open Access

\section{Abstract}

Jujube fruit cracking has become a major concern in jujube production. It can affect fruit quality and yield and crop productivity, resulting in significant economic loss. Recent advances in jujube fruit cracking research provide opportunities to improve our understanding of the impacts of environmental factors and plant physiological metabolism on jujube fruit cracking. In this article, we have developed a novel systemic modeling software for jujube fruit cracking. The potential function and value of this modeling software are presented. Current issues and future research directions in the modeling of jujube fruit cracking system are also discussed. To our knowledge, this is the first functional and/or integrated modeling software developed for the management of jujube fruit cracking.

\section{Keywords}

Modeling Software, Jujube Fruit Cracking System, Circadian Clock, Metabolic Pathway Modeling

\section{Introduction}

Jujube fruit cracking has become a major concern in jujube production. It can affect fruit quality and yield and crop productivity, resulting in significant economic loss. Fruit cracking occurs at the maturation period when favorable environmental conditions such as rainfalls are present. Changes in environment factors, and fertilizer input as well as changes in plant physiological metabolism contribute to the development of fruit cracking, resulting in fruit surface cracking, flesh exertion and acidifying decay (Figure 1 and Figure 2). Fruit cracking currently poses severe challenges to jujube producers.

\footnotetext{
${ }^{*}$ Corresponding authors.
} 


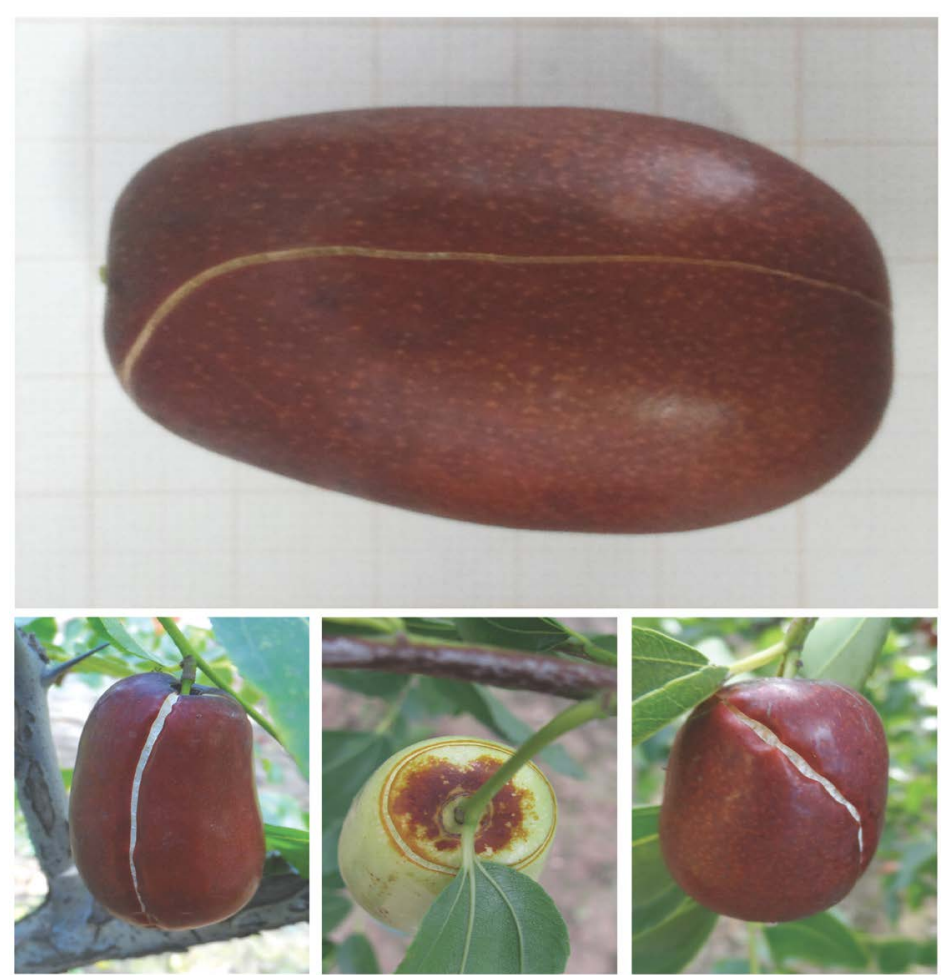

Figure 1. Symptoms of jujube fruit cracking on the Ziziphus jujuba Mill. 'Hupingzao’, one of the most important local cultivars originated in Shanxi, China: typical longitudinal cracking type (bottom-left), roll-ring cracking type (bottom-middle) and irregular cracking type-oblique cracking (bottom-right).

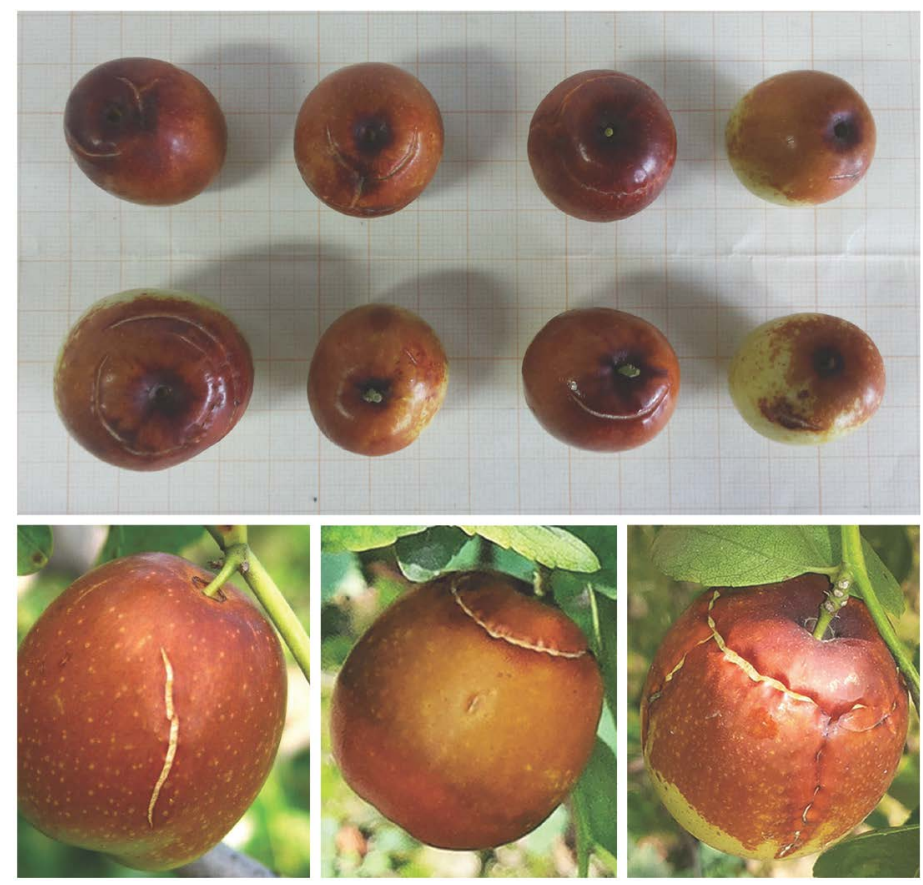

Figure 2. Symptoms of jujube fruit craking on the Ziziphus jujuba Mill. 'Pozao', another very important local cultivar originated in Hebei, China: longitudinal cracking type (bottom-left), roll-ring cracking type (bottom-middle) and irregular cracking type-longitudinal cracking + roll ring cracking (bottom-right). 
The development and the adoption of a systemic modeling approach that help to understand the functions of external and internal factors are one of the solutions to the successful management of jujube fruit cracking. Recent advances in our understanding of plant physiology from the molecular to the whole-plant levels and behavior and functional relationships between multiple elements in the whole system or organism make it possible towards this goal [1]-[3]. The emergence of bioinformatics has facilitated the analysis of complicated networks and assisted in identifying novel components and biological pathways [4]. Mathematical modeling of these pathways helps to generate new hypotheses and experimental designs, improving our understanding of biochemical processes in plants [5] [6]. In the context of computational systems biology, modeling can be used to identify connections between elements in a network and to predict the spatio-temporal dynamics of a system through simulations of model variables [7]. Kinetic modeling on the use of lipase for the hydrolysis of fats and oils, and the prediction of the hydrolysis rate, although they are still lacking, can offer advantages over conventional chemical reactions. A Ping-Pong Bi Bi model with substrate inhibition by water has been used to describe the reaction mechanism and kinetic characteristics of lipase-catalyzed hydrolysis of palm olein [8]. Modeling studies do not necessarily end at the model development stage. New information can also be generated from analyzing performance and behavior of the model itself [4]. In this article, we present some salient examples of modeling studies in plant systems. Comprehensive reviews of plant morphogenesis and growth modeling have been published [9] [10]. Stockle et al. (2003) developed CropSyst, a multi-year, multi-crop, daily time step cropping systems simulation model, which can serve as an analytical tool to study the effects of climate, soil, and management on cropping systems productivity. CropSyst is able to better simulate soil, water and nitrogen budgets, crop growth and development, crop yield, residue production and decomposition, soil erosion by water, and salinity [11]. More recently, functional-structural plant models, which stem from early plant architectural models, have emerged to incorporate with the effects of shoot structure on light interception to better understand the availability of biomass for the growth of individual organ and the whole plant [12]-[14]. Grima and Schnell (2008) reviewed four distinct theoretical and simulation frameworks, showing that taking noise and space into account not only improves quantitative prediction accuracy but also may lead to qualitatively different physiological predictions, unaccounted by classical deterministic models [15]. In a stochastic functional-structural model developed by Kang et al. (2008) to simulate plant development and growth, it is clearly indicated that the number of organs (internodes, leaves and fruits) produced by the model is not only a key intermediate variable for biomass production computation, but also an indicator of model complexity [16]. Furthermore, Harrington et al. (2010) developed a new curves modeling on the effectiveness of temperature for chilling and forcing based on their data and published information, which can predict the effectiveness over a wide range of temperatures [17].

Objective of this article was to develop a novel functional and/or integrated modeling software for jujube fruit cracking that can serve as a viable modeling tool to help our understanding of the jujube plant network structure and their functional mechanisms. The results of this research demonstrate, for the first time, how to use modeling approaches to better manage jujube fruit cracking by manipulating external environment and other inputs and internal physiological metabolism parameters. Some perspectives on the directions of future development of jujube fruit cracking modeling systems were discussed.

\section{Development of the Modeling Software}

There have been increased concerns about the vulnerability of agricultural production to climate change. The potential impacts of climate change on crop production have been widely analyzed and hypothesized by using crop models and climate change scenarios, but little evidence of the observed impacts of climate change on crop production has been reported [18]. Over the past decade there has been an increased interest in developing methodology that can study intracellular reactions, in particular those focusing on the determination of kinetic parameters [19]. Typically, data obtained from experimental assays are input into a mathematical model before it can be interpreted meaningfully. The bulk of these models are based on the macroscopic and deterministic models of classical physical chemistry [20]. A prominent example of this analysis is the characterization of enzymes using the Michaelis-Menten equation [21]. The use of any type of modeling methodology implicitly assumes that a number of physical, chemical or biochemical constraints are satisfied [15]. So external environment and inputs including climate, soil and management as well as internal physiological metabolism parameters are 
among the most important factors for the development of such plant modeling systems. This article reports the functional and/or integrated modeling software for jujube fruit cracking (Figure 3). The external environment and inputs and internal physiological metabolism parameters (Figures 3(A)-(B)) are presented as follows:

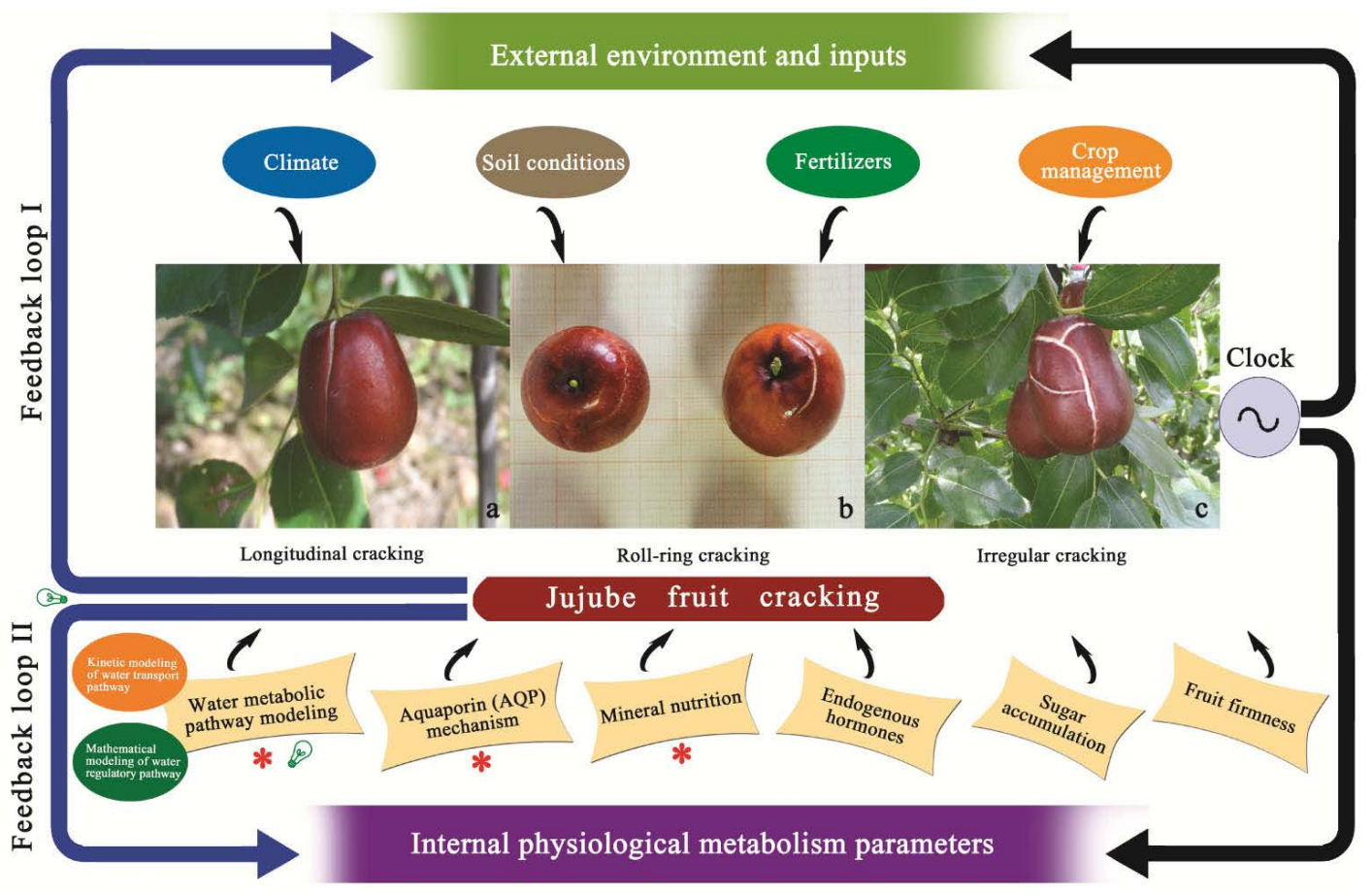

(A)
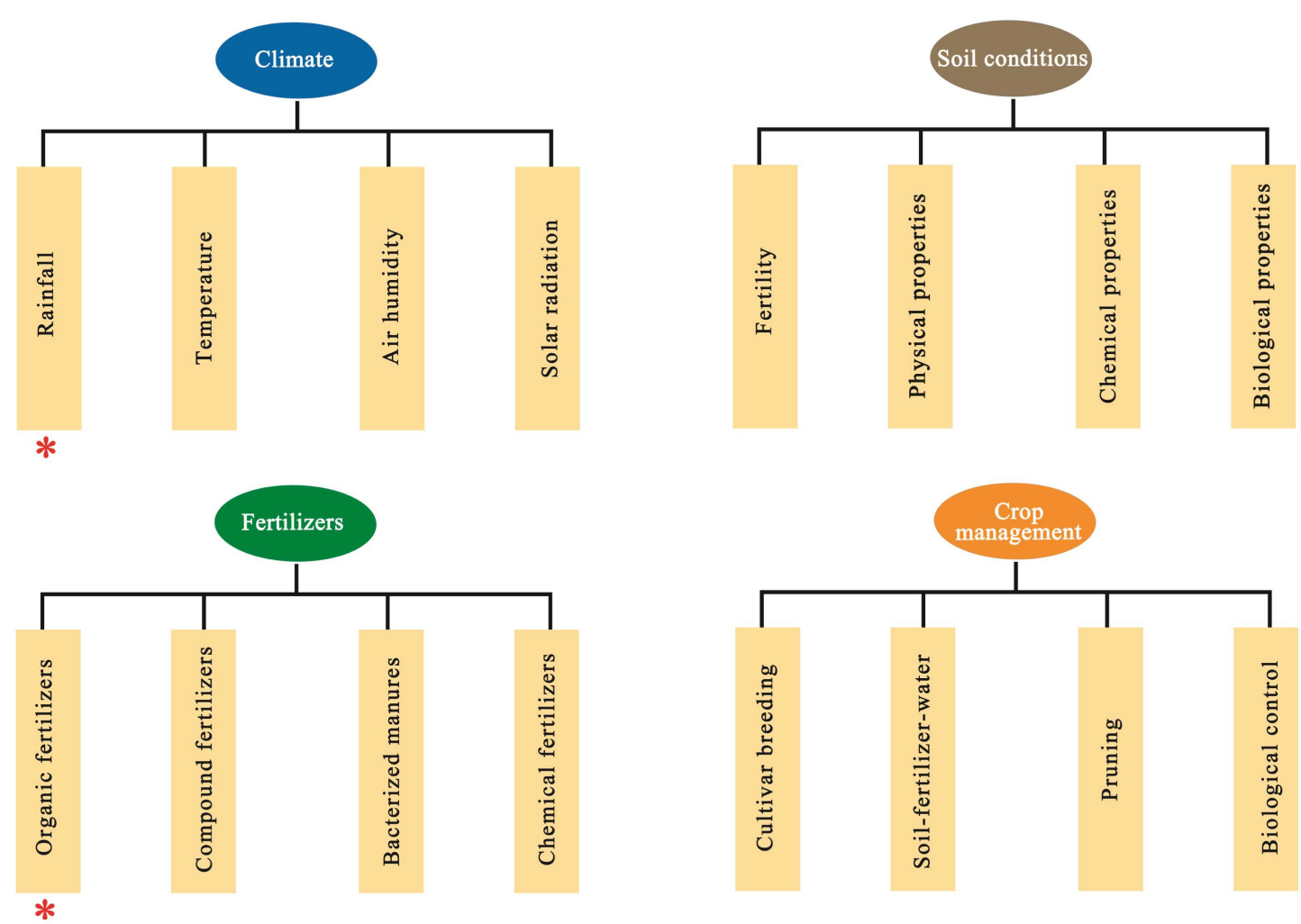

(B) 


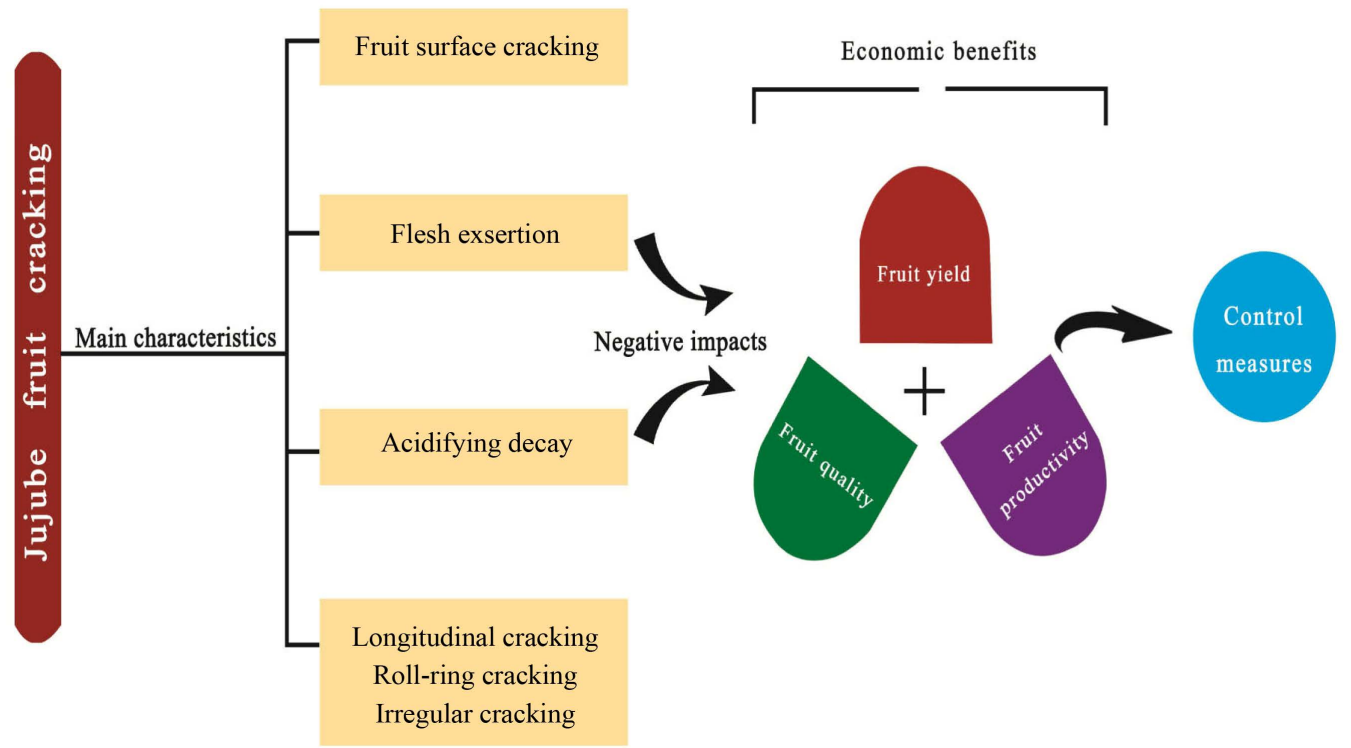

(C)

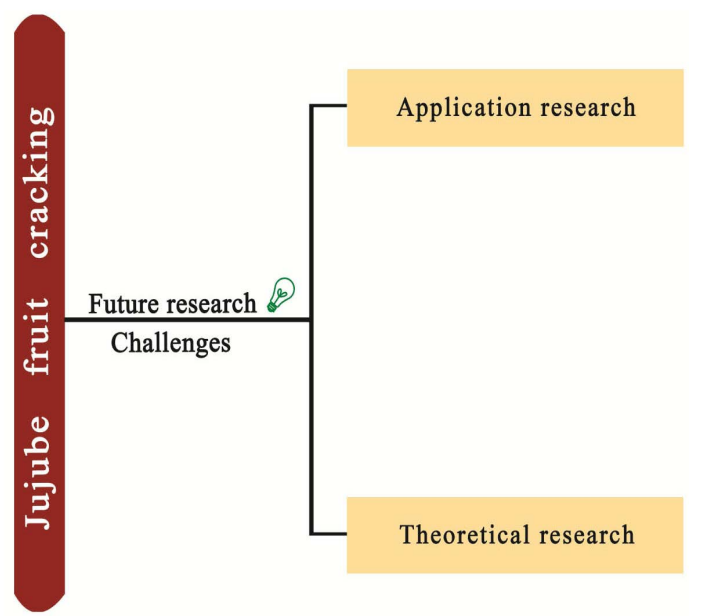

(D)

Figure 3. A novel functional and/or integrated modeling software for jujube fruit cracking. (A) Temporal regulation of jujube fruit cracking by external and internal cues is 'gated' by the circadian clock. Circadian clock system that oscillates in a daily cycle of $24 \mathrm{~h}$ as a key controller has a central role in the signaling network, integrating external environmental and input cues and internal clock-driven lights up jujube fruit cracking system. The 'assembly' model of jujube fruit cracking types and clock (shown in Figure 3(A)-middle) like a 'battery pack' as a bold and innovative idea here can provide much more power for whole jujube fruit cracking system. The 'assembly' model demonstrated here as a novel power supply system in plant can also better control the power source of plant system for assuring normal system operation. Blue arrows represent feedback loops from jujube fruit cracking to external environment and inputs and to internal physiological metabolism parameters, including feedback loop I and feedback loop II, which indicate the effects of external and internal factors on jujube fruit cracking and clearly reflect the relationships between jujube fruit cracking and external environment and inputs and internal physiological metabolism. Thick black arrows represent circadian clock as a key controller gates the temporal regulation of jujube fruit cracking by external environment and inputs and internal physiological metabolism parameters, which may bridge a wide range of spatio-temporal scales and better reflect the physiology at the cross-level interactions; (B) External environmental and input cues systematically presented in our model; (C) (D) Further important information of system is clearly demonstrated, including the main characteristics, negative impacts, control measures of jujube fruit cracking (C) and the future research and challenges of our model on jujube fruit cracking system (D). (a) Longitudinal cracking; (b) Roll-ring cracking; (c) Irregular cracking. *The most important factors, which can systematically reflect the relationships between external and internal factors and jujube fruit cracking, including the positive and negative impacts. Highlights the areas that have been shown for the first time in our newly developed model. 


\subsection{External Environment and Inputs}

- Climate factor: rainfall, temperature, air humidity and solar radiation;

- Soil conditions: fertility, and physical, chemical and biological properties;

- Fertilizer use: organic fertilizers, compound fertilizers, bacterized manures and chemical fertilizers;

- Crop management: cultivar breeding, soil-fertilizer-water, pruning and biological control.

Where: rainfall is chosen as the first most important factor since it has direct, detrimental effects on jujube fruit cracking at the maturation period. Over-uptaking water in jujube fruit under rainfall conditions can cause fruit surface cracking, flesh exsertion and acidifying-decay. Organic fertilizer is chosen as the second most important factor since it may have either positive and negative effects on the control of jujube fruit cracking if organic fertilizer is used properly or improperly, respectively. Proper use of organic fertilizer, especially the use of microbial technology for organic waste management and bioremediation, sustainable soil management, composing and formulation of microbial inoculant, can improve soil conditions, increase fertility utilization rate, and induce plant resistance against fruit cracking, resulting in improved quality, yield and productivity of jujube crop.

\subsection{Internal Physiological Metabolism Parameters}

- Water metabolic pathway modeling: kinetic modeling of water transport pathway and mathematical modeling of water regulatory pathway;

- Aquaporin (AQP) mechanism;

- Mineral nutrition;

- Endogenous hormones;

- Sugar accumulation;

- Fruit firmness.

Where: water metabolic pathway modeling in jujube fruit is chosen as the third most important factor in the modeling software. There are two focused areas of this factor: 1) kinetic modeling in water transport pathway and 2) mathematical modeling in water regulatory pathway in jujube fruit. For the kinetic modeling in water transport pathway, the modeling of water uptake will be built first to reveal the relationships between cracking rate and water absorption rate; then the kinetic modeling in water transport will be built to better understand the pathway in jujube fruit and the jujube fruit cracking. The development of mathematical modeling in water regulatory pathway serves as a complementary tool to the experimental approach, which will help us to better understand the biological systems. Such modeling will also provide a new tool to describe the water dynamical change in signaling and to understand the relationship between water regulatory pathway in fruit and the jujube fruit cracking. Aquaporin (AQP) mechanism in jujube fruit is chosen as the fourth most important factor since it can effectively mediate the water transport pathway and water regulatory pathway in fruit. This factor represents the high-efficiency of gene expression in Aquaporin (AQP). Mineral nutrition in jujube fruit is chosen as the fifth most important factor since the balance of mineral nutrition is required for the healthy development of jujube fruit. Both lack and excessive enrichment of mineral nutrition in jujube fruit may cause jujube fruit cracking.

In this article, we demonstrate, for the first time, two feedback loops based on jujube fruit cracking with external environment and inputs and internal physiological metabolism parameters for our modeling software. Feedback loop I reveals the effects of external environment and inputs on jujube fruit cracking. The input of some external factors will cause both detrimental and beneficial effects. For instance, overuse of fertilizers may cause environmental pollution and the wasting of resources, whereas optimized use of fertilizers can minimize environmental pollution and reduce production costs.

Feedback loop II reveals the effects of internal physiological metabolism parameters on jujube fruit cracking. This loop stimulates the water dynamical changes to reflect the water metabolic pathway in fruit. Feedback loop II can be used to indicate the wasting of resources as it may need to receive excessive more mineral nutrition and endogenous hormones to enhance its resistance and to maintain its basis metabolic ability. Feedback loop I and feedback loop II interact each other directly or indirectly.

\subsection{Main Characteristics of Jujube Fruit Cracking (Figure 3(C))}

Jujube fruit cracking is a physic process of mechanical ruptures in fruit peel caused by the insufficient tensile 
strength of fruit peel to sustain the growing strength of its inner fresh. It is a reaction from the impacts of unfavorable environment and fruit flesh growth. With the development of fruit, water potential in fruit flesh decreases while its water absorption ability increases. Cell senescence and apoptosis in fruit peel lead to the loss of the ability of the cells to absorb water. Once water deposits in the surface of fruit, water tends to pour into the fruit driven by the force of water potential gradient, causing an increase in growing pressure of fruit flesh that is beyond the ability of fruit peel to sustain, leading to the fractures in fruit peel. Fruit surface cracking, flesh exsertion, and acidifying decay are three main characteristic symptoms of jujube fruit cracking. Fruit cracking provides favorable conditions for the anthracnose pathogen and other bacterial pathogens to infect, which accelerates the decay and deterioration of jujube fruit. Generally, there are three types of fruit cracking: longitudinal cracking (Figure 3(A)-a), roll-ring cracking (Figure 3(A)-b), and irregular cracking (Figure 3(A)-c).

\subsection{Main Negative Impacts of Jujube Fruit Cracking (Figure 3(C))}

Jujube fruit cracking can severely affect fruit quality and reduce fruit yield and productivity, resulting in economic loss.

\subsection{Main Advantages of this Modeling Software for Jujube Fruit Cracking (Figure 3(C))}

- Prioritize to select and use cracking-resistant cultivars;

- Intelligent use of plant hormones, plant growth regulators, and chemical reagents;

- Balance the tree body nutritions;

- Optimized the use of fertilizers, and control the use of water and fertilizers, preferably mixed in organic fertilizers;

- Improve soil conditions;

- Proper pruning;

- Improve the comprehensive management level;

- Better application of novel rain-shelter-cultivation facilities and rational utilization of bagging technology.

\subsection{The Outlook of Jujube Fruit Cracking System Modeling (Figure 3(D))}

International concerns regarding food security and a competing demand for the production of biofuels have highlighted the need for renewed efforts to increase crop yield and productivity [22]. We face increasing survival pressure due to rapidly-growing world population, serious environmental pollutions and over-wasting of resources. Hence, the development and adaptation of plant organic waste management and bioremediation technologies for control of jujube fruit cracking, notably in the areas of jujube fruit and bioproducts processing, can significantly relief the pressure of environmental pollutions and wasting of resources. Here we present two key potential approaches of reusing the waste cracked-fruit resources. Cracked jujube fruit can be processed and used as jujube fruit powder, jujube fruit juice, jujube wine, jujube jam, sweet jujube candy, canned jujube, and dried jujube. The essence of nutrition in cracked jujube fruit can also be extracted and processed as biological health care products and natural medicines. More theoretical research is needed to include other external environmental factors and metabolic or signaling pathways to further improve this jujube fruit cracking system modeling software.

\section{Discussion}

Application of modeling techniques of engineering and physical sciences will help to understand how a suite of different biological, physical, and chemical signals interact and regulate plant growth and development. Indeed, these techniques have been already used in plant modeling such as the description of water, gas, and nutrition transport in the fruit, root, and stem [23] [24]. There is also a potential need to use a modular approach to improve existing models as practiced in climate modeling [25]. Modeling approaches can be applicable to crop research at different levels. Models that integrate genetic, molecular and biochemical information can facilitate our understanding of complex behavior such as pathway integration whereas models that cross scales from the molecular, cellular to whole plant or field level have enormous potential in crop improvement and crop yield forecasting [26]. With the global demand for food projected to increase $70 \%-100 \%$ by 2050 , innovation approaches to enhance crop robustness and yield will play an increasingly important role in meeting the nutritional 
demands of a growing world population [22] [27]-[29]. We need to look at different examples of models that cover various levels of biological organization, systems and scales. As demonstrated in our study as an example, simulation-based models are useful and viable in identifying new network components and interactions that are not always intuitive from experimental data. This is a good example of how experimental data are required to construct a model, and model prediction can in turn drive new hypotheses for testing in the lab and the field.

In this study, a circadian clock system has been incorporated into our modeling software for jujube fruit cracking. Such clock is a complicated system that can coordinate external stimuli and an internal timing mechanism to optimize the growth and development of jujube fruit. Further investigation into the functions of known clock components and the elucidation of interactions between the clock and input and output pathways will help us to understand how plants thrive in a predictably changing environment. As illustrated by recent studies in crop plants, these insights are likely to have important implications for agricultural improvement.

As illustrated in this study, the development and use of reliable and viable modeling techniques can improve our understanding and management of jujube fruit cracking. To our knowledge, this is the first report to help our understanding of the jujube fruit cracking system.

\section{Conclusion}

The systemic modeling software proposed here can provide a novel tool for the effective management of jujube fruit cracking.

\section{Acknowledgements}

We thank China National Forestry Industry Research Special Funds for the Public Welfare (No. 201004041) and Shanxi Province Science and Technology Development Grant Programs (No. 20110311012-4 and 20130311021-2) for providing financial support for this research.

\section{Conflicts of Interest}

The authors declare no conflict of interest.

\section{Author Contributions}

YBH conceived and designed the study, and drafted the manuscript. YQS, JL and CFT participated in the design and coordination of the study. XGZ reviewed and revised the design and manuscript, and prepared the final version of the manuscript. LLL supervised the study and provided the key information for design. All authors read and approved the final manuscript.

\section{References}

[1] Baldazzi, V., Bertin, N., de Jong, H. and Genard, M. (2012) Towards Multiscale Plant Models: Integrating Cellular Networks. Trends in Plant Sciences, 17, 728-736. http://dx.doi.org/10.1016/j.tplants.2012.06.012

[2] Band, L.R., Fozard, J.A., Godin, C., Jensen, O.E., Pridmore, T., Bennett, M.J. and King, J.R. (2012) Multiscale Systems Analysis of Root Growth and Development: Modeling beyond the Network and Cellular Scales. Plant Cell, 24, 3892-3906. http://dx.doi.org/10.1105/tpc.112.101550

[3] Mitra, K., Carvunis, A.R., Ramesh, S.K. and Ideker, T. (2013) Integrative Approaches for Finding Modular Structure in Biological Networks. Nature Reviews Genetics, 14, 719-732. http://dx.doi.org/10.1038/nrg3552

[4] Chew, Y.H., Smith, R.W., Jones, H.J., Seaton, D.D., Grima, R. and Halliday, K.J. (2014) Mathematical Models Lights Up Plant Signaling. Plant Cell, 26, 5-20. http://dx.doi.org/10.1105/tpc.113.120006

[5] Kitano, H. (2002b) Systems Biology: A Brief Overview. Science, 295, 1662-1664. http://dx.doi.org/10.1126/science.1069492

[6] Di Ventura, B., Lemerle, C., Michalodimitrakis, K. and Serrano, L. (2006) From in Vivo to in Silico Biology and Back. Nature, 443, 527-533. http://dx.doi.org/10.1038/nature05127

[7] Kitano, H. (2002) Computational Systems Biology. Nature, 420, 206-210. http://dx.doi.org/10.1038/nature01254

[8] Chew, Y.H., Chua, L.S., Cheng, K.K., Sarmidi, M.R., Aziz, R.A. and Lee, C.T. (2008) Kinetic Study on the Hydrolysis of Palm Olein Using Immobilized Lipase. Biochemical Engineering Journal, 39, 516-520.

http://dx.doi.org/10.1016/j.bej.2007.10.019 
[9] Chickarmane, V., Roeder, A.H.K., Tarr, P.T., Cunha, A., Tobin, C. and Meyerowitz, E.M. (2010) Computational Morphodynamics: A Modeling Framework to Understand Plant Growth. Annual Review of Plant Biology, 61, 65-87. http://dx.doi.org/10.1146/annurev-arplant-042809-112213

[10] Mirabet, V., Das, P., Boudaoud, A. and Hamant, O. (2011) The Role of Mechanical Forces in Plant Morphogenesis. Annual Review of Plant Biology, 62, 365-385. http://dx.doi.org/10.1146/annurev-arplant-042110-103852

[11] Stockle, C.O., Donatelli, M. and Nelson, R. (2003) CropSyst, a Cropping Systems Simulation Model. European Journal of Agronomy, 18, 289-307. http://dx.doi.org/10.1016/S1161-0301(02)00109-0

[12] Yan, H.P., Kang, M.Z., de Reffye, P. and Dingkuhn, M. (2004) A Dynamic, Architectural Plant Model Simulating Resource-Dependent Growth. Annals of Botany, 93, 591-602. http://dx.doi.org/10.1093/aob/mch078

[13] Godin, C. and Sinoquet, H. (2005) Functional-Structural Plant Modeling. New Phytologist, 166, 705-708. http://dx.doi.org/10.1111/j.1469-8137.2005.01445.x

[14] Vos, J., Marcelis, L.F.M. and Evers, J.B. (2007) Functional-Structural Plant Modelling in Crop Production: Adding a Dimension. In: Vos, J., Marcelis, L.F.M., Visser, P.H.B., Struik, P.C. and Evers, J.B., Eds., Functional-Structural Plant Modelling in Crop Production, Springer, Dordrecht, 1-12.

[15] Grima, R. and Schnell, S. (2008) Modeling Reaction Kinetics Inside Cells. Essays in Biochemistry, 45, 41-56. http://dx.doi.org/10.1042/BSE0450041

[16] Kang, M.Z., Cournede, P.H., de Reffye, P., Auclair, D. and Hu, B.G. (2008) Analytical Study of a Stochastic Plant Growth Model: Application to the GreenLab Model. Mathematics and Computers in Simulation, 78, 57-75. http://dx.doi.org/10.1016/j.matcom.2007.06.003

[17] Harrington, C.A., Gould, P.J. and St Clair, J.B. (2010) Modeling the Effects of Winter Environment on Dormancy Release of Douglas-Fir. Forest Ecology and Management, 259, 798-808. http://dx.doi.org/10.1016/j.foreco.2009.06.018

[18] Tao, F.L., Yokozawa, M., Xu, Y.L., Hayashi, Y. and Zhang, Z. (2006) Climate Changes and Trends in Phenology and Yields of Field Crops in China, 1981-2000. Agricultural and Forest Meteorology, 138, 82-92. http://dx.doi.org/10.1016/j.agrformet.2006.03.014

[19] Cornish-Bowden, A. and Cardenas, M.L. (2001) Enzyme Kinetics. Methods, 24, 95-96.

[20] Schnell, S. and Turner, T.E. (2004) Reaction Kinetics in Intracellular Environments with Macromolecular Crowding: Simulations and Rate Laws. Progress in Biophysics \& Molecular Biology, 85, 235-260. http://dx.doi.org/10.1016/j.pbiomolbio.2004.01.012

[21] Schnell, S. and Maini, P.K. (2003) A Century of Enzyme Kinetics: Reliability of the $\mathrm{K}_{\mathrm{M}}$ and $\mathrm{V}_{\max }$ Estimates. Comments on Theoretical Biology, 8, 169-187. http://dx.doi.org/10.1080/08948550302453

[22] Borlaug, N. (2007) Feeding a Hungry World. Science, 318, 359. http://dx.doi.org/10.1126/science.1151062

[23] De Schepper, V. and Steppe, K. (2010) Development and Verification of a Water and Sugar Transport Model Using Measured Stem Diameter Variations. Journal of Experimental Botany, 61, 2083-2099. http://dx.doi.org/10.1093/jxb/erq018

[24] Ho, Q.T., Verboven, P., Verlinden, B.E. and Nicolai, B.M. (2010) A Model for Gas Transport in Pear Fruit at Multiple Scales. Journal of Experimental Botany, 61, 2071-2081. http://dx.doi.org/10.1093/jxb/erq026

[25] Collins, W.D., Bitz, C.M., Blackmon, M.L., Bonan, G.B., Bretherton, C.S., Carton, J.A., Chang, P., Doney, S.C., Hack, J.J. and Henderson, T.B. (2006) The Community Climate System Model Version 3 (CCSM3). Journal of Climate, 19, 2122-2143. http://dx.doi.org/10.1175/JCLI3761.1

[26] Chew, Y.H. and Halliday, K.J. (2010) A Stress-Free Walk from Arabidopsis to Crops. Current Opinion in Biotechnology, 22, 1-6.

[27] Godfray, H.C., Beddington, J.R., Crute, I.R., Haddad, L., Lawrence, D., Muir, J.F., Pretty, J., Robinson, S., Thomas, S.M. and Toulmin, C. (2010) Food Security: The Challenge of Feeding 9 Billion People. Science, 327, 812-818. http://dx.doi.org/10.1126/science.1185383

[28] Parry, M.A. and Hawkesford, M.J. (2010) Food Security: Increasing Yield and Improving Resource Use Efficiency. Proceedings of the Nutrition Society, 69, 592-600. http://dx.doi.org/10.1017/S0029665110003836

[29] Tester, M. and Langridge, P. (2010) Breeding Technologies to Increase Crop Production in a Changing World. Science, 327, 818-822. http://dx.doi.org/10.1126/science.1183700 